\title{
CLINICAL AND LABORATORY PROFILE OF CHILDREN OF AGE GROUP 6 MONTHS TO 5 YEARS WITH IRON DEFICIENCY ANEMIA ADMITTED IN A TERTIARY CARE CENTRE
}

Leela Kumari $P^{1}$

\author{
${ }^{1}$ Additional Professor, Department of Paediatrics, SAT Hospital, Medical College, Trivandrum.
}

\begin{abstract}
Iron deficiency is the commonest micronutrient deficiency worldwide. It is preventable and treatable. Iron deficiency in a child can affect the physical growth as well as the cognitive functions since Iron is essential for growing brain. So early detection and correction of Iron deficiency is very essential. This descriptive study was conducted in 155 anemic children of age 6 months to 5 years admitted in a tertiary care centre. Objective was to study the clinical and laboratory profile. This study showed high prevalence of anemia in male children compared to females. Higher grades of anaemiawas found in those taking diet deficient in Iron rich food and those not having periodic deworming. Mild anemia was noted in $34.2 \%$, Moderate in $52.9 \%$ severe in $12.9 \% .47 .5 \%$ were in the age group 3-5 years. Significant association was found between Iron deficiency and Febrile seizures. $18.7 \%$ of study participants had under nutrition and $11 \%$ had first degree stunting.
\end{abstract}

KEYWORDS: Iron Deficiency, Serum Ferritin, Haemoglobin, Febrile Seizures.

HOW TO CITE THIS ARTICLE: Leela Kumari P. "Clinical and Laboratory Profile of Children of Age Group 6 Months to 5 Years with Iron Deficiency Anemia Admitted in A Tertiary Care Centre". Journal of Evolution of Medical and Dental Sciences 2015; Vol. 4, Issue 92, November 16; Page: 15736-15738, DOI: 10.14260/jemds/2015/2271.

INTRODUCTION: Iron deficiency is the commonest micronutrient deficiency worldwide. It is preventable and treatable.1,2 Estimates suggest that over one third of the world's population suffer from anaemia, especially iron deficiency anaemia

The World Health Organization (WHO) has estimated that globally 1.62 billion people are anemic, with the highest prevalence of anemia (47.4\%) among preschool-aged children; of these 293 million children, 89 million live in India. ${ }^{2}$ Thus India continues to be one of the countries with very high prevalence of anaemia.

The National Family Health Survey NFHS-3 reveals the prevalence of anaemia to be $70-80 \%$ in children, $70 \%$ in pregnant women and $24 \%$ in adult men. NFHS-3 data shows that the prevalence of anaemia in children in Kerala is $45 \%{ }^{2,3,4,5}$

Anaemia has well known adverse effects on physical and cognitive performance of individuals. Children with anaemia can be lethargic, with poor scholastic performance and recurrent infections. It can compromise growth, development and can depress immune function..$^{2,6}$

Early detection and timely correction of anemia is essential for the physical growth and cognitive development of children. Hence this study regarding the clinical and laboratory profile anemic children is very relevant.

METHODS: This study was conducted in the paediatrics ward of SAT Hospital, Medical College, Thiruvananthapuram, a

Financial or Other, Competing Interest: None

Submission 26-10-2015, Peer Review 27-10-2015,

Acceptance 05-11-2015, Published 13-11-2015.

Corresponding Author:

Dr. Leela Kumari $P$,

Additional Professor

Department of Paediatrics,

SAT Hospital, Medical College, Trivandrum.

E-mail: leela_suresh2005@yahoo.co.in

DOI:10.14260/jemds/2015/2271. tertiary care referral and teaching hospital for a period of 2years from February 2012. Ethics clearance was obtained from the institutional Ethics committee. Sample size calculated using the formula $\mathrm{N}=4 \mathrm{PQ} / \mathrm{D}^{2} \mathrm{P}=$ prevalence $=45$, $\mathrm{Q}=100-\mathrm{P}, \mathrm{D}=8$ (Precision) was 155 . Children of age group 6 months to 5 years admitted in Paediatric ward having anemia (Diagnosed by WHO criteria) were included for study. Children having anemia due to other conditions like haemolytic anemia, aplastic anemia, chronic systemic diseases and chronic infections were excluded from the study. Consecutive cases satisfying the inclusion and exclusion criteria were included for the study. After informed consent, a detailed history was taken. Complete physical examinations including the anthropometric measurements were done. Relevant haematologic and biochemical investigations were done. These investigations done include blood haemoglobin, blood indices (MCV, MCH, MCHC, RDW) using automated analyser and peripheral smear examination was done by the expert pathologist. Serum Ferritin estimation was done by the ELISA method. Grading of anemia was done by the WHO criteria. Mild $\mathrm{Hb}$ value $10-10.9 \mathrm{gm} / \mathrm{dl}$, moderate $\mathrm{Hb}$ value 7 $9.9 \mathrm{gm} / \mathrm{dl}$ and severe less than $7 \mathrm{gm} / \mathrm{dl}$. Stool microscopy and occult blood test was done in all cases Data were entered in MS Excel. Completeness was checked. Analysis was done using the statistical software SPSS version 17.

RESULTS: Grade of Anaemia: Out of 155 children with anaemia $34.2 \%$ had mild anemia, moderate anemia in $52.9 \%$, and severe in $12.9 \%$.

\begin{tabular}{|c|c|c|}
\hline Grade & Frequency & Percentage \\
\hline Mild $(\mathrm{Hb} 10-10.9 \mathrm{~g} / \mathrm{dl})$ & 53 & 34.2 \\
\hline Moderate $(\mathrm{Hb} 7-9.9 \mathrm{~g} / \mathrm{dl})$ & 82 & 52.9 \\
\hline Severe $(\mathrm{Hb}<7 \mathrm{~g} / \mathrm{dl})$ & 20 & 12.9 \\
\hline Total & $\mathbf{1 5 5}$ & $\mathbf{1 0 0}$ \\
\hline
\end{tabular}




\section{Age Distribution:}

\begin{tabular}{|c|c|c|}
\hline Age group & Frequency & Percent \\
\hline 6m-1yr & 19 & 12.3 \\
\hline $1 \mathrm{yr}-3 \mathrm{yr}$ & 62 & 40.0 \\
\hline 3yr-5yr & 74 & 47.7 \\
\hline Total & $\mathbf{1 5 5}$ & $\mathbf{1 0 0}$ \\
\hline
\end{tabular}

\section{Gender Distribution:}

\begin{tabular}{|c|c|c|}
\hline Sex & Frequency & Percent \\
\hline Male & 98 & 63.2 \\
\hline Female & 57 & 36.8 \\
\hline Total & $\mathbf{1 5 5}$ & $\mathbf{1 0 0 . 0}$ \\
\hline
\end{tabular}

Male dominance was noted

\section{Socioeconomic status (Modified Kuppuswamy's socioeconomic status scale)}

\begin{tabular}{|c|c|c|}
\hline Social class & Frequency & Percent \\
\hline Class 1 & 1 & .6 \\
\hline Class 2 & 6 & 3.9 \\
\hline Class 3 & 88 & 56.8 \\
\hline Class 4 & 57 & 36.8 \\
\hline Class 5 & 3 & 1.9 \\
\hline Total & $\mathbf{1 5 5}$ & $\mathbf{1 0 0 . 0}$ \\
\hline
\end{tabular}

Majority of cases belonged to Social class 3(56.8\%) and $4(36.8 \%)$

Anthropometry: $18.7 \%$ of cases were under weight, $11 \%$ were having first degree stunting.

Diet: $62 \%$ had Iron deficient diet. Of these children with Iron deficient diet, $77.1 \%$ had severe anemia and $22.9 \%$ had mild anemia. Periodic deworming only in $33.8 \%$ of cases. Higher grades of anemia (Moderate to severe) was found in these children.

Co-morbidities: Acute Respiratory infections 60\%, febrile seizures $22.5 \%$, Urinary tract infections $13.5 \%$, others $6 \%$

Haematologic findings: Hypochromic microcytic blood picture was observed in $87 \%$ of children with moderate to severe anemia. Mean corpuscular volume(MCV) of $<80 \mathrm{fl}$ was found in $93.2 \%$ of children with moderate to severe anemia. Mean corpuscular haemoglobin (MCH) value of $<23 \mathrm{pgm}$ was found in $98.4 \%$ children with moderate to severe anemia. MCHC of $<30 \mathrm{gm} / \mathrm{dl}$ was found in $100 \%$ of children with moderate to severe anemia.Red Cell Distribution width (RDW) of $>15 \%$ was found in $77 \%$ of children with moderate to severe anemia. Mean Serum Ferritin was $35.7 \mathrm{ngm} / \mathrm{ml}$.

Statistically significant association was found between Febrile seizures and low serum Ferritin level. $63 \%$ of children with Febrile seizures had serum Ferritin value $<30 \mathrm{ngm} / \mathrm{ml}$.

Stool microscopy revealed round worm ova in $5.8 \%$ of cases and stool occult blood was positive in $2 \%$ of cases.

DISCUSSION: In the present study of 155 anemic children, $47.7 \%$ were of age $3-5$ years, $40 \% 1$-3yrs, $12.3 \%$ of age 6 months to 1year. Children of 6 months to 1year had mild anemia predominantly and children of 1-5 years had moderate to severe anemia mainly. The World Health Organization (WHO) has estimated that, globally, 1.62 billion people are anemic, with the highest prevalence of anemia (47.4\%) among preschool-aged children; of these 293 million children, 89 million live in India. ${ }^{2}$

In the present study $63 \%$ anemic children were males while $36 \%$ were female. No gender difference was noted in anemic children in NFFHS 3 study, male $69 \%$ and females $69.9 \% .7,8$

In the present study $57 \%$ children belonged to lower middle class according to Kuppuswami scale, 37\% belonged to upper lower class, $4 \%$ belonged to upper middle class and $2 \%$ belonged to lower class. Whereas NFHS3 data showed

prevalence of anemia more in children of low socio economic class. ${ }^{9,7,10}$

$62 \%$ of Anemic children were not taking Iron rich food. Of these $77.1 \%$ had moderate to severe anemia and $22.9 \%$ had mild anemia. NFHS-3 study shows that only $15 \%$ were taking Iron rich foods. ${ }^{7.11}$

Only $33.8 \%$ of children had periodic deworming and those who were not dewormed had higher grades of anemia. $18.7 \%$ of children with anemia were underweight and $11 \%$ had first degree stunting. In the study done by Savitha Nagaraj etal stunting was noted in $28.7 \%$ of anemic children. ${ }^{12}$

Significant association was found between febrile seizures and low serum Ferritin level. Similar observation was there in the study by Leela Kumari, MKC Nair etal among children of age group 6 months to 3 years presenting with Typical Febrile Seizures. ${ }^{13.14 .15}$

SUMMARY: Iron deficiency anemia is a major Public Health problem. Out of 155 anemic children studied, $63 \%$ had mild anemia, 31\% had moderate anemia and 5\% had severe anemia. Children of age 3-5 yrs were found to have higher percentage of moderate to sevre anemia while those of 6 months to 1 year had more frequency of mild anemia. Children who were not taking Iron rich food and those who were not having periodic deworming were found to have higher grades of anemia (Moderate to severe). So periodic dewormig and Iron rich food should be stressed in children of 6 months to 5 years. More number of male children were found to be anaemic (63\%) compared to females (36\%). So equal importance should be given for prevention and treatment of anaemia in male children also. Significant association was found between febrile seizures and low serum Ferritin. So all children with Febrile seizures should be screened for Iron deficiency and should be treated.

\section{REFERENCES:}

1. Benoist B, McLean E, Egli I, Cogswell, eds. International conference on nutrition Rome, ICN ,1992.

2. Nelson $M$,White $\mathrm{F}$ Haemoglobin, Ferritin, and iron intake in British children Br.J Nutr;1993;70:147-155.

3. Robert M. Kleigman. Nelson Text Book of Paediatrics $20^{\text {th }}$ edition ; Chapter 44:280-290.

4. Worldwide Prevalence of Anaemia1993-2005. Geneva, Switzerland: World Health Organization; 2008. Available at:whqlibdoc.

Who.int/publications/2008/97892 41596657_eng.pdf. 
5. Harrisons Principle of Internal Medicine $18^{\text {th }}$ edition Harrison Online Anemia and polycythemia Chapter 57.

6. Tatala S, Svenberg et al, Low dietary iron availability-a major cause of anemia, a nutrition survey in Lindi, Tanzania, Am J Clinical nutrition 1998;68(1),171.

7. NFHS-3 Chapter 10 anemia and nutrition.

8. Combination of anemia, high altitude challenge outcomes for children with pneumonia. Science Daily. November 11, 2013.

9. Iron Deficiency Anaemia Assessment, Prevention, and Control A guide for programme managers WHO/NHD/01.3.

10. Ritu Gupta, Ravinder K. Gupta Current Issues for the Prevention of Iron Deficiency Anemia Amongst Young Children JK science October-December 2004Vol. 6 No.4.
11. WHO Global Database on Iron Deficiency and Anemia, Micronutrient Deficiency Information System. Geneva, World Health Organization.

12. Savitha Nagaraj, N. S. Prashanth et al Determinants of Anemia Among Young Children in Rural Indiapublished in American Academy of Paediatrics June 14, 2010.

13. P Leela Kumari, MKC Nair, SM Nair, Lalitha Kailas and S Geetha Iron Deficiency as a Risk Factor for Simple Febrile Seizures-A Case Control Study Indian Pediatr 2012;49: 17-19.

14. Naveed-ur-Rehman, Billoo AG Association between iron deficiency anemia and febrile seizures J Coll Physicians Surg Pak. 2005 Jun; 15(6):338-40.

http://www.ncbi.nlm.nih.gov/pubmed/1592483.

15. B.K. Dr. AGARWAL S. K. et al Journal Dr. MAHESHWARI of Clinical and Diagnostic Research. 2011 Apr, Vol5(2):324-327. 